\title{
LA ASISTENCIA SANITARIA A LOS HERIDOS Y ENFERMOS DEL EXILIO REPUBLICANO ESPAÑOL EN FRANCIA: DE LA IMPROVISACIÓN INICIAL A LOS CAMPOS DE CONCENTRACIÓN (ENERO-SEPTIEMBRE 1939)
}

\author{
Rubén Mirón-González \\ Facultad de Terapia Ocupacional, Logopedia y Enfermería de Talavera de la Reina. Toledo / Universidad de Castilla La Mancha \\ Ruben.Miron@uclm.es \\ ORCID iD: https://orcid.org/0000-0003-4788-6083 \\ Carmen González-Canalejo \\ Facultad de Ciencias de la Salud / Universidad de Almería \\ Canalejo@ual.es \\ ORCID iD: https://orcid.org/0000-0003-0843-1289
}

Recibido: 6 abril 2017; Aprobado: 20 marzo 2018.

Cómo citar este artículo/Citation: Mirón-González, Rubén y González-Canalejo, Carmen (2018), "La asistencia sanitaria a los heridos y enfermos del exilio republicano español en Francia: de la improvisación inicial a los campos de concentración (enero- septiembre 1939)", Asclepio, 70 (2): p234. https://doi.org/10.3989/asclepio.2018.18

RESUMEN: El final de la Guerra Civil Española en Cataluña supuso un punto de inflexión en la vida de casi medio millón de refugiados españoles que traspasaron la frontera pirenaica en el invierno de 1939. En este gran afluente, existieron más de 13.000 heridos y enfermos que tuvieron que ser atendidos por toda la geografía francesa. Con esta investigación, se visibiliza cuáles fueron los itinerarios de los heridos, dónde fueron atendidos y qué características tuvo la asistencia sanitaria hasta que la mayoría de los pacientes fueron reconducidos a campos de concentración situados en el sur de Francia. Nos encontramos ante una realidad compleja que ha sido abordada con documentación localizada en una docena de archivos históricos franceses, testimonios directos y prensa general. Entre los resultados, cabe destacar la necesidad de improvisación de la III República Francesa en materia asistencial, ya que el $70 \%$ de los refugiados fueron asistidos en centros acondicionados para la ocasión. En los hospitales, quienes atendieron fueron en su mayoría profesionales sanitarios españoles. Realizaron su labor de una manera digna, a pesar de las restricciones de las autoridades francesas hacia lo que ellos consideraron "el problema español".

PALABRAS CLAVE: Exilio; Guerra Civil Española; Refugiados; Francia; Asistencia Sanitaria. HEALTHCARE TO WOUNDED AND SICK REFUGEES IN THE SPANISH REPUBLICAN EXILE IN FRANCE:
FROM THE INITIALIMPROVISATION TO THE CONCENTRATION CAMPS (JANUARY-SEPTEMBER 1939)

ABSTRACT: The end of the Spanish Civil War in Catalonia influenced the lives of almost half a million of Spanish refugees that crossed the Pyrenean border in the winter of 1939. In this large migration wave, more than 13,000 wounded and sick people had to be treated within French territory. With this research, we examine the routes of the wounded, the places where they were treated, and the features of their healthcare before they were transported to the concentration camps in southern France. This information has been analysed using documentation of 12 French historical archives, direct testimonials and general press. The results emphasize the Third French Republic's ability to improvise in the healthcare field, where 70\% of the refugees were treated in specially equipped healthcare centres. Those who treated refugees in hospitals were mostly Spanish healthcare professionals. They carried out their work in a dignified manner, despite restrictions from French authorities towards what they considered to be "the Spanish problem".

KEY WORDS: Exile; Spanish Civil War; Refugees; France; Healthcare.

Copyright: (C) 2018 CSIC. Este es un artículo de acceso abierto distribuido bajo los términos de la licencia de uso y distribución Creative Commons Reconocimiento 4.0 Internacional (CC BY 4.0). 


\section{INTRODUCCIÓN}

Desde que en 1970 aparecieron los primeros estudios del exilio político de la Guerra Civil Española (1936-1939), mucho ha sido el camino recorrido y el esfuerzo historiográfico dedicado a la reconstrucción de uno de los periodos más trágicos de España (Cabeza Sánchez-Albornoz, 2000; Hoyos Puente, 2012; Font Agulló y Gaitx Moltó, 2014). En esta primera etapa historiográfica, se situaron numéricamente los movimientos migratorios hacia Francia (Rubio, 1974; Llorens, 1976) y se comenzó a explicar el fenómeno del exilio español mediante el uso de fuentes periodísticas y testimoniales (Wingeate Pike, 1969; Stein, 1981). Es en los años 90 cuando comenzaron a surgir los primeros monográficos, fruto de una mayor catalogación archivística. Sin embargo, desde el punto de vista sanitario apenas se dedicaron unas páginas al análisis de este fenómeno (Rafaneau Boj, 1995; Dreyfus-Armand, 2000; Peschanski, 2002).

Entrados en el siglo XXI, el riguroso trabajo de Francisco Guerra sobre la medicina en el exilio abrió una nueva línea de investigación dentro de la gran temática socio-sanitaria (Guerra, 2003). Desde entonces, ha incrementado el número de investigadores que han abordado los aspectos sanitarios y los colectivos profesionales en el exilio (González Canalejo, 2009; Martínez Vidal y Zarzoso Orellana, 2010; Ruiz-Berdún y Bladé i Font, 2016), los espacios asistenciales (Malo, 2009; Harana, 2012; Martínez Vidal, 2013a; Alted Vigil y Fernández Martínez, 2014; Mirón-González y González-García, 2017), la morbi-mortalidad y la intervención clínica dentro de los campos de concentración (Peschanski, 2005; Martínez Vidal, 2013b; Souche, 2013) o la política sanitaria del gobierno de la III República Francesa (Parello, 2014). Otros autores como Hervás i Puyal $(2004,2014)$, si bien no han abordado el exilio propiamente dicho, sí han estudiado los aspectos sanitarios previos al final de la Guerra Civil en Cataluña. El pánico ante el avance de las tropas franquistas entre enero y febrero de 1939 motivó el traslado a Francia de enfermos y heridos, así como de ciegos y grandes inválidos, desde todos los puntos fronterizos de Cataluña, en condiciones calamitosas. Sin estas claves, resultaría imposible entender la existencia misma de un colectivo tan numeroso susceptible de tener que ser atendido en los hospitales franceses, ni tampoco la crisis sanitaria correspondiente, más allá de la crisis humanitaria propiamente dicha.

A pesar de estos avances, apenas es conocido el itinerario asistencial que siguieron los más de 13.000 heridos y enfermos evacuados desde la retaguardia republicana española, en el invierno de 1939. Un camino que vino marcado por la improvisación del gobierno de la III República Francesa y que marcó la vida de aquellos que en la documentación localizada constan como "incurables", "inválidos" e "ineptos" para su integración como mano de obra. Por lo tanto, esta investigación tiene como objetivo visibilizar cuáles fueron los itinerarios de los heridos y enfermos del exilio republicano español en Francia entre enero y septiembre de 1939.

Como apunta Paula Simón en su tesis doctoral, los testimonios directos de los refugiados sirven para visibilizar los conflictos sociales a los que se vieron inmersos, entre los que se encuentran también los conflictos sanitarios (Simón Porolli, 2011, p. 427). Es por ello que en este trabajo recurrimos a algunos de los testimonios publicados hasta la fecha (Stein, 1981; Grando, Queralt y Febrés, 2004). No obstante, el grueso documental de este trabajo proviene de los 12 archivos históricos franceses consultados ${ }^{1}$. Esto ha permitido acceder a correspondencia del Ministerio del Interior, responsable directo de los refugiados españoles, del Ministerio de Salud Pública y del Ministerio de Asuntos Extranjeros. Asimismo, se han analizado los informes de las inspecciones departamentales de Higiene, incluyendo la correspondencia de las direcciones hospitalarias con las prefecturas y los ayuntamientos. Se ha consultado también el Boletín de la Unión de Mujeres de Francia y el Boletín de la Academia de Medicina de Francia, así como una parte de la prensa general francesa ${ }^{2}$. Como limitación, cabe decir que se podría incorporar un mayor número de fuentes archivísticas sanitarias francesas. Sin embargo, su envergadura y dispersión, así como su análisis, rebasan con mucho los límites de esta investigación.

\section{EVACUACIÓN DE HERIDOS Y ENFERMOS: LA LLEGADA A FRANCIA}

Según datos de la prefectura de los Pirineos Orientales, podemos situar los orígenes de la "Retirada" 3 el 20 de enero de 1939 (todas las fechas desde aquí en adelante se refieren a este año, salvo que se especifique lo contrario). En dicha fecha se identificó un incremento considerable de mujeres, niños y ancianos en las fronteras con Cataluña. Desde la llegada de los primeros refugiados, comenzaron a acondicionarse campos o centros de recepción en los municipios de Cerbère, Boulou, Bourg-Madame y Latour-de-Carol ${ }^{4}$. El 25 de enero, la prensa francesa manifestó la posibilidad de un movimiento masivo de población desde Barcelona ${ }^{5}$. Ese mismo día salió el último tren con 
heridos desde Barcelona, dirección Portbou (Hervás i Puyal, 2004, pp. 275-279). Mientras tanto, el municipio de Prats-de-Mollo recibió el aviso de que los hospitales de Camprodón iban a ser evacuados. Esta evacuación se estimó en unos 4.000 enfermos y heridos, motivo por el cual se movilizó la población francesa para ayudar (Pruja, 2003, p. 35; Souche, 2013, p. 13).

Las primeras indicaciones oficiales fueron enviadas por el Ministerio del Interior el 27 de enero. Al día siguiente, el Ministerio de Salud Pública avisó de que se haría un control para detectar posibles casos de viruela y tifus exantemático ${ }^{6}$, enfermedades que ya se venían controlando en la España republicana desde el inicio de la Guerra Civil ${ }^{7}$. Afortunadamente, el 26 de febrero comenzaron a funcionar en Boulou, dos puestos sanitarios de emergencia organizados por la Union des Femmes de France (UFF), organización de enfermeras de la Cruz Roja Francesa ${ }^{8}$, en colaboración con los servicios de higiene departamental de los Pirineos Orientales. Los puestos sanitarios tuvieron una dotación de 12 enfermeras de la UFF, entre las que se encontraba la presidenta de dicha organización:

"Nuevo ejemplo de tiempos de hordas bárbaras, todo un pueblo huyendo, sin orden, sin objetivo, sin víveres... He visto esos desafortunados traspasar los puertos nevados de los Pirineos; he visto, en Boulou, nuestras 12 enfermeras de Perpiñán, bajo la dirección de su presidenta, cuya alabanza es insuperable, la Señorita Marqui, cuidando, abasteciendo, vacunando día y noche hasta el agotamiento extremo" ${ }^{\prime \prime}$.

Lamentablemente, las vacunas se agotaron al tercer día, decidiendo que se continuara con dicha labor en los centros de alojamiento, por lo que no se pudo asegurar la prevención ${ }^{10}$. Tampoco se llegaron a cumplir las medidas de aislamiento ${ }^{11}$ ni de desparasitación por motivos económicos ${ }^{12}$, con el riesgo que supuso para la propagación del tifus exantemático. Las primeras indicaciones sanitarias acabaron fracasando y la situación en el sur de Francia comenzó a ser preocupante. El gobierno de la República francesa se vio en la necesidad de pedir ayuda al gobierno británico ${ }^{13}$. El "riguroso plan" del que se enorgullecía el 23 de enero Raoul Didkowsky, prefecto de los Pirineos Orientales, comenzó a desmoronarse a menos de una semana ${ }^{14}$.

Mientras que el grupo de mujeres, niños y ancianos fueron evacuados hacia el interior de Francia, los civiles varones y los milicianos fueron retenidos en los puestos fronterizos. Una situación que se alargó 10 días hasta que se les permitió el paso el 5 de febrero en Cerbère y el 6 de febrero en Le-Perthus. Para esas fechas, los afluentes civiles y militares se mezclaron en las fron- teras formando una única columna de personas. Por mucho que el gobierno francés intentara poner orden, empezó a visibilizarse el "problema español"15.

Al llegar a suelo francés, las palabras "Allez! Allez!", "blessé?, blessé?" pronunciadas por los gendarmes quedaron grabadas para siempre en la memoria de los refugiados. De los 453.000 españoles que cruzaron la frontera entre el 20 de enero y el 14 de febrero, según los propios datos del Ministerio francés de Asuntos Extranjeros ${ }^{16}$, la cifra de heridos superó las 13.000 personas. Estos datos concuerdan con el testimonio de Eduard Pons Prades, sargento afecto al Comisariado de Sanidad de Guerra, citado por Solé y Tuban (2011, p. 13), quien señalaba que en el momento de la ofensiva franquista funcionaban en Cataluña 110 hospitales y 40 balnearios que acogían a 20.000 heridos, de los cuales se evacuaron hacia Francia unos 12.500.

Continuando con el número de heridos y enfermos que fueron atendidos en Francia entre enero y marzo de 1939, existen diferencias entre distintos autores que han tratado el tema y las fuentes primarias localizadas ${ }^{17}$. Según anunció la prensa francesa en febrero de 1939, el número de refugiados atendidos en ese momento en los hospitales franceses era de 10.000 . Esta cifra contrasta con las estadísticas registradas en la estación de Cerbère, que cifraba en 13.275 el número de heridos y enfermos que pasaron por la frontera en esta misma fecha ${ }^{18}$, cifra que guarda relación con fuentes directas diplomáticas de las Sociedad de las Naciones, en junio de $1939^{19}$. La realidad fronteriza también quedó registrada por una de las enfermeras francesas del Hospital de Saint-Louis de Perpiñán:

“¿Cómo podría empezar el relato de lo que sucedió? Llegaban andando desde Argelès, algunos de ellos, con toda clase de heridas terribles. Y algunos habían venido andando desde Barcelona o Figueras con esas mismas heridas. Otros venían en tren o ambulancia. Habían cortado ramas de los árboles e improvisado parihuelas [camillas]. Sus escayolas estaban llenas de barro. Trataban de impedir que sus sucias ropas se les deshicieran, atándolas con cuerdas a su alrededor, porque pensaban que un trozo de ropa sucia era mejor que nada. Muchos de ellos tenían extremidades en estado gangrenoso, y todos estaban demacrados, hambrientos y exhaustos. Me pregunté cómo unos hombres podían soportar tanto y seguir caminando con la esperanza de que al fin alguien pudiera ayudarles. Cuando recibimos a nuestros primeros pacientes, estuve trabajando treinta y seis horas seguidas, luego descansé seis, y volví a trabajar un turno de otras treinta y seis. Y podía haber estado trabajando así durante semanas, sin que se hubiera notado apenas. Había demasiados heridos" (Stein, 1983, p. 46). 
La evacuación de los heridos estuvo en todo momento organizada desde la Jefatura de Sanidad republicana española. Una semana antes de la caída de Barcelona se trasladó el puesto de mando sanitario desde la capital catalana a Gerona (Hervás i Puyal, 2004, p. 275). En la población de Llançà (Gerona) se habilitó un tren hospital, con una gran dotación, según los propios informes sanitarios franceses (Cavaillon y Leclainche, 1939, p. 332). Los heridos y enfermos fueron trasladados en trenes desde todos los puntos de Cataluña hasta Port Bou para su evacuación a Francia. Lamentablemente, en la estación internacional de Cerbère, los trenes tuvieron que ser desalojados a medida que llegaban, debido al cambio de ancho de vía entre España y Francia. Hubo que bajar a todos los heridos, retenerlos en la estación y esperar a que fueran evacuados en trenes franceses. Una situación que llegó a provocar el hacinamiento de hasta 2.900 heridos el 7 de febrero ${ }^{20}$. Estas evacuaciones se realizaron de forma escalonada. Cuando los refugiados llegaron a los departamentos de acogida, estaban en un estado físico y mental lamentable ${ }^{21}$.

"El primer tren que llegó de Latour-de-Carol transportaba mujeres, ancianos y niños hacinados dentro de viejos vagones de mercancías con paja en el suelo. Se alojó a esas pobres gentes de cualquier manera en los pasillos de espera de la estación. A continuación llegaron los heridos, varios cientos, y todo un ejército. No había nada previsto para alojar y alimentar todas esas gentes. Las mujeres, lo niños y los heridos algunos de los cuales murieron allí mismo, «inauguraron» el cementerio de Enveitg, fueron evacuados por tren progresivamente. Pero los hombres válidos y los soldados debían permanecer allí"22.

La distribución de los heridos por la geografía francesa tuvo sus peculiaridades. Evidentemente, las poblaciones francesas con mayor carga de acogida fueron las de las regiones del sur (Ver Gráfico1). Esto respondía a motivos de cercanía, pero también al deseo de las autoridades francesas de no alejar los milicianos de España para posibles repatriaciones.

\section{EL ACONDICIONAMIENTO DE ESPACIOS ASISTENCIALES}

El primer refugiado español del que tenemos constancia ingresó el 27 de enero en el hospital civil de Perpiñán (Saint-Jean). Dos días más tarde, la oleada de ingresos fue masiva, en todos los hospitales civiles departamentales ${ }^{24}$. La masificación de enfermos y el desbordamiento de trabajo de los sanitarios hicieron que, de la noche a la mañana, se dejara de registrar datos de los pacientes ingresados. Determinada información como fractura de fémur, hemorragia, herida penetrante de bala o bronquitis fue sustituida por la palabra "réfugié", que se repite decenas de veces en

Gráfico 1. Regiones francesas que recibieron refugiados heridos y/o enfermos. Enero-septiembre de $1939^{23}$

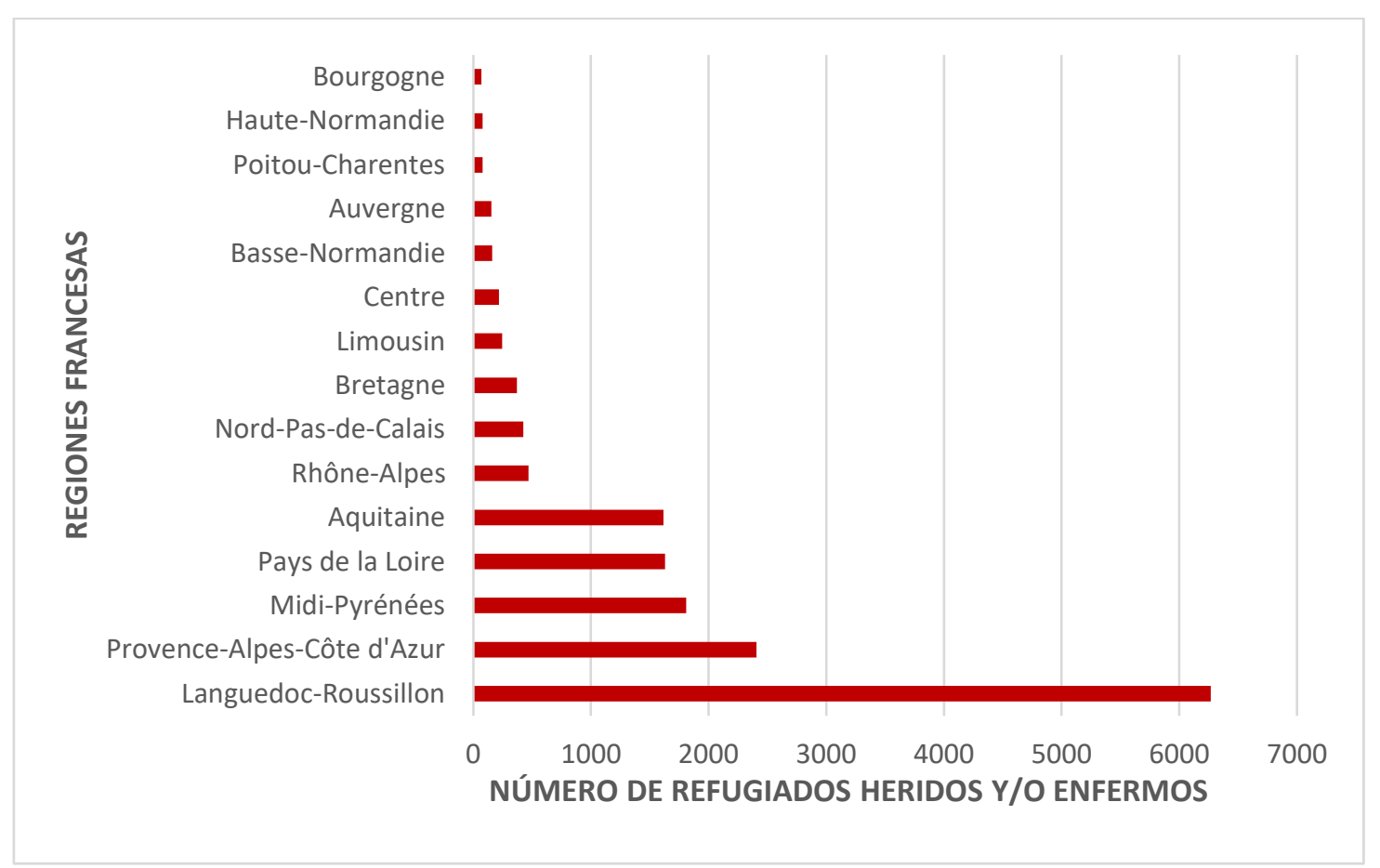


los libros de registro del hospital ${ }^{25}$. Durante este primer mes, el hospital de Perpiñán llegó a atender hasta 404 refugiados, de los que 61 perdieron la vida, lo que corresponde a una media de 13 ingresos diarios y una mortalidad del $10 \%$. Cifras que son, en realidad, la punta del iceberg, ya que muchos refugiados fueron atendidos en lugares donde no se llevó a cabo ningún registro de entrada. Se desconoce la cifra real de los que fallecieron ${ }^{26}$.

Mientras que en los Pirineos Orientales se ofertaron 80 camas hospitalarias, su vecina Ariège puso a disposición 138. En 22 días el departamento de Ariège atendió a 42 heridos, de los cuales murieron 7. Dicho de otra forma, en este hospital hubo una media de 2 ingresos diarios y una mortalidad del $16 \%$. Cabe la posibilidad de que en los centros más pequeños no existieran los mínimos recursos para garantizar la asistencia como en otros departamentos con mayor número de población, tal y como se constata en el caso del hospital de Aude, donde se argumentó la imposibilidad de atención a los refugiados por motivos económicos ${ }^{27}$.

Sea como fuere, el caso es que los hospitales públicos existentes en la geografía francesa no pudieron dar solución al problema sanitario que planteaba la realidad de los refugiados enfermos y heridos ${ }^{28}$. Ello hizo necesario el acondicionamiento de viejos establecimientos para incrementar el número de camas. Entre enero y septiembre de 1939, alrededor del $30 \%$ de los refugiados fueron atendidos en centros ya existentes como hospitales, hospicios, preventorios o sanatorios $^{29}$. El resto fue asistido en espacios habilitados a tal fin que se fueron improvisando a medida que se iban colapsando los primeros. Hoteles, villas, institutos, cines, salas de fiesta, colegios, castillos, campamentos de verano, barcos, refugios... pasaron a albergar infraestructuras sanitarias; incluso se improvisaron establos para las mujeres parturientas. Gran parte de esos espacios continuaron como espacios sanitarios durante la Segunda Guerra Mundial, proporcionando asistencia a los prisioneros de los campos de concentración franceses.

A corto plazo, la capacidad hospitalaria de los Pirineos Orientales también se vio incrementada con el acondicionamiento de la escuela Saint-Louis, de Perpiñán y la reapertura del Antiguo Hospital Militar. Estos centros llegaron a disponer de entre 450 y 680 camas respectivamente $^{30}$. El 2 de febrero de aquel año, se anunció en prensa que ambos centros ya estaban disponibles. Dos semanas más tarde, el Antiguo Hospital Militar volvió a ser noticia debido a la presencia de 56 casos de fiebre tifoidea en este establecimiento ${ }^{31}$. El hacina- miento, la falta de higiene y la desnutrición fueron caldo de cultivo para la irrupción de otras enfermedades transmisibles, como el tifus exantemático. Las precarias condiciones de estos hospitales provocaron que parte de la plantilla de sanitarios que allí trabajó también se contagiara $^{32}$. A este respecto, es muy ilustrativo el testimonio de Jobert-Dalligny, directora general adjunta de personal de la UFF, en su informe:

"Vi, en Perpiñán, nuestros equipos turnándose en el hospital civil, en la maternidad, en la guardería municipal y en ese antiguo hospital militar edificio reabierto, sin camas, sin agua, sin ni siquiera las necesidades más esenciales de higiene dónde los tifoideos yacían sobre la paja y dónde la enfermera daba sus cuidados de rodillas" ${ }^{\prime \prime 3}$.

La crisis sanitaria, a consecuencia del desbordamiento y la improvisación, queda reflejada en la pésima organización de los centros hospitalarios franceses tras la llegada de más de 13.000 heridos y enfermos. Desde la llegada de los refugiados, el asunto fue gestionado por el Ministerio de la Defensa Nacional y de Guerra. Apenas existieron indicaciones y se delegó la responsabilidad en las prefecturas, teniendo que recurrir a sus Inspecciones Departamentales de los Servicios de Higiene bajo la vigilancia de autoridades militares ${ }^{34}$. Hasta el 3 de marzo, no existió una regulación por parte del Ministerio de Sanidad Pública de la asistencia hospitalaria de los refugiados españoles. Con respecto a la mortalidad, las cifras se ocultaron sistemáticamente en las relaciones numéricas que mandaron los prefectos al Ministerio del Interior ${ }^{35}$.

\section{LOS BARCOS HOSPITALES}

A mediados de febrero, todos los centros asistenciales estaban literalmente abarrotados. Mientras que los refugiados con problemas médicos podían ser atendidos en los mismos puestos fronterizos o esperar a que fueran evacuados hacia el interior, los milicianos graves con fracturas abiertas, hemorragias internas o heridas penetrantes, necesitaban asistencia quirúrgica inmediata. En este sentido, los equipos sanitarios de socorro aplicaron un principio bastante sencillo: si no podían acercar los heridos a los quirófanos, los quirófanos debían ser aproximados a los heridos. Con este propósito, y a escasos días de abrirse la frontera a los milicianos, en el puerto de Marsella se acondicionaron cuatro barcos que cumplieron la función de hospitales quirúrgicos. Se trata de los barcos: Asni, Maréchal-Lyautey, Patria y Providence. Los dos primeros llegaron a Port-Vendres el 11 de febrero, mientras que los dos últimos-permanecieron en Marsella ${ }^{36}$. 
En los barcos habilitados se llegaron a atender más de 4.000 milicianos $^{37}$. El barco Maréchal-Lyautey fue el más grande de los cuatro, con una capacidad de 1.200 camas (Arnaud, 1939). El Asni tenía una capacidad previa de 300 camas, pero se acondicionaron $800^{38}$. Lamentablemente, el hacinamiento impidió una asistencia eficiente siendo ésta tachada de penosa y precaria por parte de la Union des Femmes de France ${ }^{39}$. Esta situación hizo que entre ambos barcos se llegara a una ocupación máxima de 1.800 heridos. Lo mismo ocurrió con los dos barcos de Marsella, donde llegaron a una capacidad máxima de 2.350 camas $^{40}$.

La asistencia en estos nuevos espacios fue frenética durante las primeras semanas. Los barcos de Port-Vendres apenas contaron con 70 enfermeras, lo que significa una enfermera por cada 26 grandes heridos ${ }^{41}$. Esta situación provocó la demanda de más personal de enfermería en los cuatro barcos por parte del colectivo médico ${ }^{42}$. El equipo de enfermería realizó hasta 500 curas diarias y colocaron más de 800 yesos; atendieron quirófanos, asistieron durante las 24 horas a los heridos sin más sueldo que la propia subsistencia ${ }^{43}$. Un trabajo agotador, tal como reflejó la enfermera Jobert-Dalligny:

"Las enfermeras de las Sociedades de la Cruz Roja deberían obligatoriamente llevar cada una un par de tijeras fuertes para cortar los vendajes. Este arsenal les limita y es tan indispensable como sus batas. El velo flotante, cofia actual de las enfermeras de la Cruz Roja, es malo: muy incómodo cuando la enfermera hace una cura a ras de suelo, se engancha dentro de las habitaciones estrechas, se vuelve peligroso dentro de las salas de operaciones. Llevar un gorro, infinitamente preferible, debería ser exigido durante el trabajo" ${ }^{44}$.

Respecto a los asistidos, es indudable que pasaron a unas mejores condiciones desde los fríos andenes de los Pirineos, pero vivieron en condiciones absolutamente penitenciarias. Aislados del mundo exterior y con registros rutinarios de los camarotes ${ }^{45}$.

\section{LA ESPAÑOLIZACIÓN DE LA ASISTENCIA}

Al cabo de unos pocos días, en los que el flujo de evacuados era continuo, el Ministerio de Sanidad Pública envió varios telegramas a los prefectos para estimular la contratación de médicos y personal auxiliar francés ${ }^{46}$. Rápidamente, existió una respuesta positiva por parte del colectivo sanitario civil, obteniendo voluntarios desde toda la geografía francesa ${ }^{47}$.

Los médicos militares franceses ocuparon las direcciones de grandes hospitales auxiliares, como fue el caso del Antiguo Hospital Militar y el de Saint-Louis de Perpiñán, aunque hubo excepciones como es el caso de la Colonia de Vacaciones de las Juventudes Laicas de Sète. Éste hospital fue co-dirigido por un médico-jefe cirujano francés y un médico-director español, antiguo director del Hospital General de Barcelona que llegó como refugiado. También compartieron la gestión, un administrador francés y un economista español ${ }^{48}$.

Aunque la dirección y gestión de los centros fue, en su mayoría francesa, se estima que, entre un 75 y un $90 \%$ de la mano de obra asistencial fue española ${ }^{50}$ (Gráfico 2). Los productos farmacéuticos fueron distribuidos por los hospitales públicos más cercanos, pero gestionados por farmacéuticos y auxiliares de farmacia españoles. Existió contratación de médicos civiles franceses, pero entre los españoles refugiados se encontraba toda clase de profesionales sanitarios quienes doblaron en cifras a los franceses. Entre los refugiados se localiza una amplia participación de practicantes, de enfermeras formadas en escuelas españolas y de enfermeras con formación práctica adquirida durante la contienda; éstas triplicaban en número a las francesas ${ }^{51}$. A medio plazo, la actividad asistencial de los españoles se convirtió en una necesidad para garantizar la asistencia de sus compatrio$\operatorname{tas}^{52}$, llegando a ser considerados indispensables por los propios prefectos ${ }^{53}$.

La españolización de la asistencia significó un abaratamiento de costes, ya que a los refugiados no se les pagaba ninguna remuneración (Tabla 1). A modo de ejemplo, en el hospital Saint-Louis de Perpiñán se sustituyó a 5 chóferes franceses que estaban cobrando 75 francos al día, por refugiados españoles. Esta realidad fue tenida en cuenta más adelante por el Ministerio del Interior, que propuso sueldos para los refugiados sanitarios cuya cuantía podía ser determinada discrecionalmente por los médicos-jefes de cada centro. En cifras, la asistencia de cada refugiado en un hospital auxiliar pasaría a costar entre 15 y 30 francos al día, mientras que en los hospitales civiles podía ascender hasta $60^{54}$.

A pesar de que se llegó a regular un sueldo irrisorio para los sanitarios españoles (Hague, 1997, pp. 151-161), la realidad es que siguieron trabajando de forma gratuita, cuestión que se prolongó hasta el verano de $1939^{55}$.

Respecto a los barcos-hospitales, también contó con dotación de enfermeras y enfermeros españoles (Arnaud, 1939). Manuel Raura, miliciano republicano que estuvo mes y medio ingresado en el barco Asni, 
Gráfico 2. Personal español y francés en diferentes centros asistenciales auxiliares. $1939^{49}$

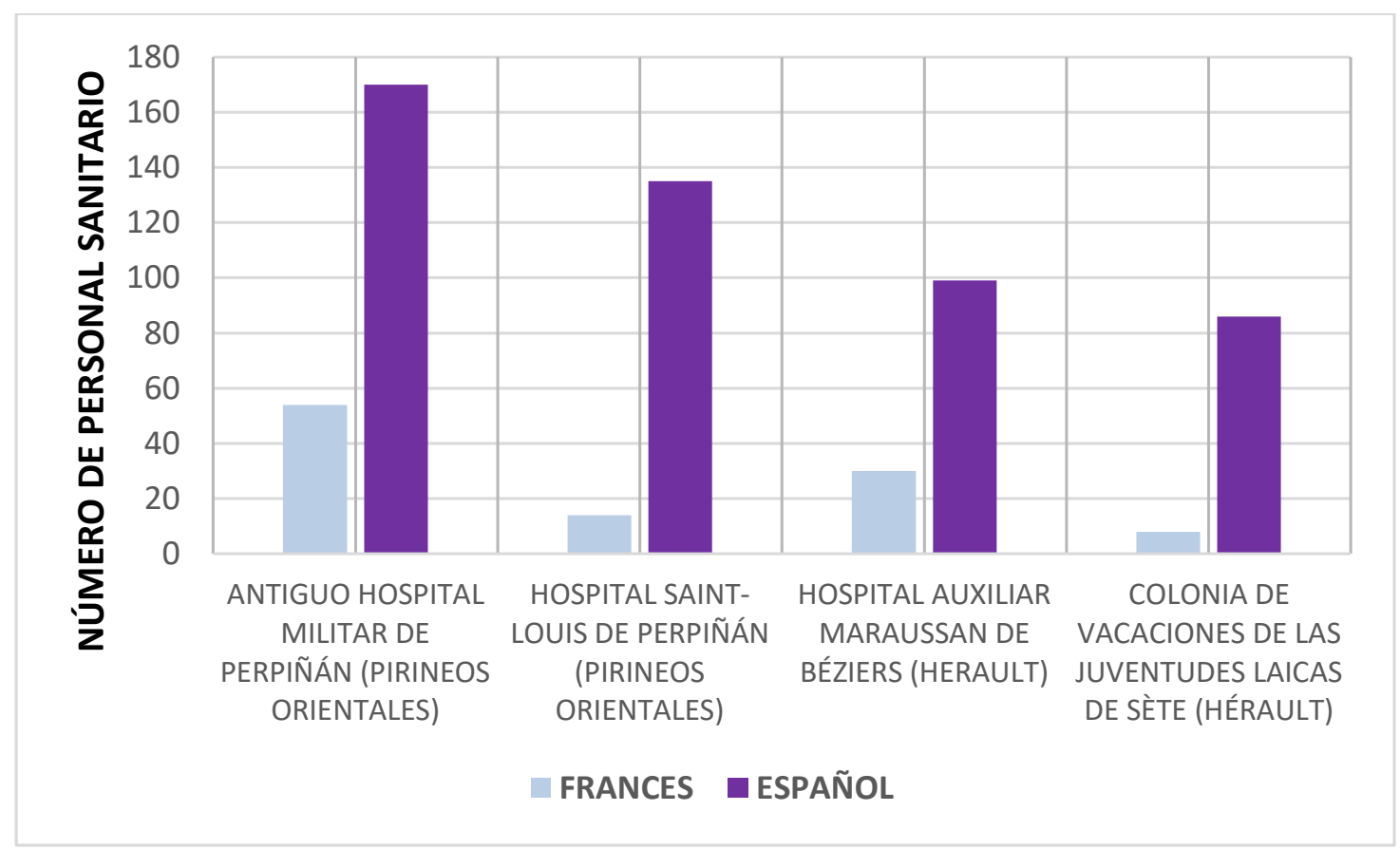

relató cómo apenas recibía la visita de enfermeras o médicos. El motivo era que él mismo se practicaba las curas, especificando que en cubierta había un bidón de 100 litros de antiséptico y un saco de algodón del que se abastecían (Solé y Tuban, 2011, p. 21). A pesar de la mano de obra barata que supuso el trabajo realizado por los sanitarios españoles, la asistencia en los barcos llegó a alcanzar los 100 francos diarios por refugiado, siempre según fuentes francesas ${ }^{56}$, motivo principal de la corta vida asistencial de estos barcoshospitales (Harana, 2012; Mirón-González y GonzálezGarcía, 2017).

\section{LOS RECORTES SANITARIOS}

El siguiente escalón asistencial lo constituyeron las enfermerías y los hospitales de los campos de concentración. Durante el primer trimestre de 1939, se dio celeridad a la evacuación de españoles ingresados en los hospitales civiles y auxiliares, al suponer un importante gasto para el Estado francés. En abril, Marc Rucart, ministro de Sanidad Pública, dio la orden de transportar hacia los campos de concentración a los enfermos ciegos y grandes amputados. Para ello solicitó a los prefectos, los listados de inválidos ingresados en los hospitales para su transporte $y$, de este modo, liberar los pabellones hospitalarios ${ }^{57}$. Un mes más tarde, este ministro ordenó a los prefectos que los heridos recuperables fueran enviados a los campos de concentración, y los grandes inválidos a establecimientos de incurables ${ }^{58}$. Esta orden se fue cumpliendo de forma escalonada por los distintos departamentos.

Como puede verse, Francia no estaba dispuesta a costear los gastos de los heridos cuyas secuelas eran irreversibles. El motivo explícito es que estos refugiados no eran útiles para los campos de trabajo. Esta política dura e inhumana continuó aplicándose a los refugiados que tenían tuberculosis u otras patologías graves para quienes no había una curación definitiva y acabaron de esta forma, convirtiéndose en un problema económico para la III República Francesa ${ }^{59}$.

A medida que la Segunda Guerra Mundial se iba perfilando, ya en el segundo semestre de 1939, los centros asistenciales fueron cerrando sus puertas para la atención de los grandes heridos de la guerra, sin más opción para los incurables que la repatriación. En el caso del departamento de Hérault las indicaciones ministeriales fueron obedecidas de forma inminente. En el mes de mayo se pasó de disponer de 1.880 camas hospitalarias, a mantener sólo las 550 del hospital auxiliar de Maraussan de Béziers, el cual funcionó como anexo al campo de concentración de Agde $^{60}$. La situación a la que les abocaba la vuelta a España, era inadmisible para estos refugiados. La cárcel y la persecución de la dictadura era algo que les desesperaba. 
Tabla 1. Remuneración diaria del personal civil francés que no pertenece a la administración pública y propuesta de pago de refugiados sanitarios españoles. Febrero, marzo y abril de 1939

\begin{tabular}{|c|c|c|c|c|}
\hline \multirow[b]{2}{*}{ PROFESIONAL SANITARIO } & \multicolumn{2}{|c|}{ JORNADA COMPLETA } & \multirow[b]{2}{*}{ MEDIA JORNADA } & \multirow{8}{*}{ 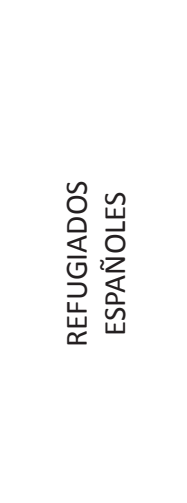 } \\
\hline & $\begin{array}{l}\text { SIN VIVIENDA } \\
\text { NI DIETA }\end{array}$ & $\begin{array}{l}\text { CON VIVIENDA } \\
\text { Y DIETA }\end{array}$ & & \\
\hline \multicolumn{4}{|c|}{ PERSONAL DESPLAZADO } & \\
\hline Médicos o farmacéuticos & 130 frs. & 80 frs. & - & \\
\hline Administradores & 130 frs. & 80 frs. & - & \\
\hline Internos en medicina o farmacia & $80 \mathrm{frs}$. & 25 frs. & - & \\
\hline Enfermeros/as & 70 frs. & 15 frs. & - & \\
\hline $\begin{array}{c}\text { Enfermeros/as de la Cruz Roja Francesa o } \\
\text { Central Sanitaria Internacional }\end{array}$ & 70 frs. & 15 frs. & - & \\
\hline \multicolumn{4}{|c|}{ PERSONAL NO DESPLAZADO } & \\
\hline Médicos o farmacéuticos & $100 \mathrm{frs}$. & - & 50 frs. & $5-10$ frs. \\
\hline Administradores & 100 frs. & - & - & - \\
\hline Internos en medicina o farmacia & 50 frs. & 15 frs. & 50 frs. & - \\
\hline Externos en medicina en función de internos & 40 frs. & 10 frs. & - & - \\
\hline $\begin{array}{l}\text { Enfermeros, enfermeras y personal } \\
\text { subalterno. }\end{array}$ & \multicolumn{2}{|c|}{$\begin{array}{l}\text { Según profesión y salarios } \\
\text { regionales }\end{array}$} & - & $0,75-1,25$ frs. \\
\hline
\end{tabular}

Fuente: Elaboración propia, documentación archivística diversa, ADTG, caja 4M/4; ANP, caja F1a/4537; ADARI, cajas 113W/22, $5 \mathrm{M} / 148$ y $113 \mathrm{~W} / 22$

Pero la respuesta de algunos jefes sanitarios franceses que gestionaban los hospitales fue tan humanitaria como contundente. Ejemplos como el del Director del hospital civil de Saint-Louis de Ax-lesThermes (Ariège), el médico-jefe del hospital auxiliar de Maraussan o el del inspector departamental de higiene de Tarascon (Ariège), a quienes los prefectos les dieron órdenes de prescindir de la plantilla de enfermeros y rescindir material ${ }^{61}$, pero no fueron cumplidas al negarse éstos a desatender a los pacientes ${ }^{62}$. Entre otras razones, los médicos argumentaron en sus respectivos informes que muchos de los trabajos de mantenimiento y limpieza estaban siendo llevados por refugiados españoles, sin ningún tipo de remuneración $^{63}$. Se trataba de directores de centros importantes, cuya cifra de asistidos llegó a ascender hasta los 1.237 pacientes $^{64}$.

A medida que pasaban los meses, las medidas de reducción de gastos continuaron su cauce. Así, en junio se fijó el número máximo de personal francés y español que podía permanecer en los hospitales auxiliares. A partir de entonces, la política del Ministerio de Sanidad Pública fue evacuar a los refugiados y trasladarlos a los campos de concentración, presionando al ministro de Asuntos Extranjeros para negociar las repatriaciones de milicianos con prioridad, tal y como ya se ha señalado, de los amputados y grandes enfermos. Todo confirma que el gobierno francés no quería tener a su cargo a ningún refugiado con gran invalidez. Por este motivo, la diplomacia francesa inició negociaciones con el gobierno franquista para tratar el tema de la repatriación de estos refugiados, a través embajador de Francia en Madrid. Estas repatriaciones ya venían ocurriendo desde prácticamente la llegada de estos refugiados a Francia, mediante aviones sanitarios, pudiendo realizar un avión hasta tres viajes por día ${ }^{65}$.

\section{CONCLUSIONES}

En el periodo comprendido entre finales de enero y marzo de 1939, en el contexto de la llegada a Francia de 453.000 exiliados españoles, atravesaron la frontera más de 13.000 enfermos y heridos españoles que fueron evacuados hacia distintos departamentos, según fuentes diplomáticas francesas. Esta situación supuso todo un reto sanitario para el Gobierno de la III República Francesa.

La asistencia sanitaria de los heridos y enfermos estuvo caracterizada por dos variables. En primer lugar, por la improvisación de los dispositivos asistenciales 
para los refugiados, que fueron articulados y gestionados por las prefecturas y los municipios. En segundo lugar, por la legislación que emanó de los Ministerios de Interior y de Salud Pública para hacer frente a la crisis sanitaria provocada por la llegada de miles de refugiados republicanos españoles.

Esta investigación pone de manifiesto tres etapas en la atención sanitaria proporcionada a los refugiados enfermos y heridos a lo largo de los tres primeros trimestres del año 1939.

En primer lugar, entre enero y febrero, la atención sanitaria estuvo marcada por la improvisación y el elevado número de enfermos y heridos. Las primeras indicaciones oficiales provinieron del Ministerio de Salud Pública y se centraron en medidas de prevención contra la transmisión de enfermedades epidémicas. No obstante, tanto la vacunación sistemática, como las medidas de aislamiento, higiene y desparasitación acabaron fracasando ante la falta de recursos materiales. A nivel asistencial, los hospitales civiles comenzaron a recibir heridos y enfermos de forma masiva, por lo que se improvisaron los primeros espacios asistenciales auxiliares en el sur de Francia, tanto en tierra como en determinadas zonas portuarias. Durante esta primera etapa las decisiones en materia asistencial fueron asumidas por las inspecciones departamentales de Higiene en colaboración con la Cruz Roja Francesa. A nivel asistencial, cabe destacar la labor de las enfermeras de la Union des Femmes de France y de la Association des Dames Françaises. No sólo estuvieron presentes en la frontera pirenaica desde los inicios del éxodo catalán, sino que trabajaron en condiciones realmente duras tanto en hospitales auxiliares como barcos hospitales.

A partir de marzo de 1939 comienza la segunda etapa, caracterizada por un notable desarrollo legislativo. Efectivamente, el Ministerio de Salud Pública se vio en la obligación de afrontar una situación excepcional para Francia, ya que la mayoría (70\%) de los refugiados heridos y enfermos estaban siendo atendidos en lugares improvisados, como los barcos-hospitales. También conviene tener en cuenta que, a pesar de que muchos de los hospitales fueron atendidos por sanitarios españoles, la asistencia de los refugiados españoles suponía un gran gasto para la economía francesa.

La tercera fase se inicia en la primavera de 1939 y está determinada por factores económicos y políticos. A partir de abril, el Gobierno francés puso en marcha una política caracterizada por el cierre sistemático de los hospitales auxiliares y el recorte del gasto sanitario, tanto de profesionales como de recursos. Esta política se recrudeció a partir del mes de junio, en un contexto político tenso que auguraba el inicio de la Segunda Guerra Mundial. Fue entonces cuando se empezó a trasladar a los pacientes a los campos de concentración y se inició la repatriación de grandes heridos e inválidos, que no iban a ser de utilidad en los campos de trabajo franceses. Esta etapa, dura, inhumana y desacorde con los valores republicanos franceses fue denunciada por numerosas organizaciones humanitarias extranjeras, y provocó la indignación de algunos directores médicos y responsables sanitarios franceses quienes elevaron su voz en ayuda de los españoles.

El verano de 1939 había comenzado y ya estaban operativos los principales campos de concentración del sur de Francia. El número de refugiados españoles retenidos había disminuido considerablemente debido a la política de repatriaciones, al traslado a los campos de trabajo y a la reagrupación familiar que se había iniciado unos meses antes.

La infraestructura sanitaria creada de manera provisional para la atención de los refugiados españoles se mantuvo en todos los departamentos franceses a lo largo de los siguientes años. Se utilizó para la atención de los judíos polacos y de otros nuevos refugiados que, al final del verano, empezaban a llegar desde otras partes de Europa. Un gran número de sanitarios españoles exiliados, que habían estado trabajando desde el principio en estos hospitales y centros auxiliares, continuaron su labor asistencial atendiendo a los nuevos perseguidos. Era el 1 de septiembre de 1939: la Segunda Guerra Mundial había comenzado.

\section{NOTAS}

1. A nivel nacional se han consultado: los Archives Nationales situados en París (ANP), Fontainebleau (ANF) y los Archives Diplomatiques du Ministère des Affaires Étrangères ( $A D M A E)$. A nivel departamental, se han consultado los Archives Départementales de Ariège (ADARI), de Aude (ADAUD), de Bouches-du-Rhône (ADBR), de Drôme (ADDR) de Haute-Garonne (ADHG), de Hérault (ADHE),

de Pyrénées-Orientales (ADPO), de Tarn (ADTA), de Tarnet-Garonne (ADTG) y de La Drôme (ADDR). Existe un análisis integral de las fuentes para el estudio sanitario del refugiado español en Mirón-González, 2015.

2. Gracias al actual avance de la digitalización documental, un gran número de periódicos franceses se pueden con- 
sultar de forma abierta a través del buscador Gallica de la Biblioteca Nacional de Francia.

3. En ocasiones este movimiento migratorio podemos encontrarlo en la historiografía del exilio como "Retirada" o "Gran Retirada". Este fenómeno corresponde al movimiento migratorio más importante hacia Francia durante la Guerra Civil Española ocurrido entre enero y marzo de 1939 (Rubio, 1974, p. 193).

4. Correspondencia del prefecto de los Pirineos Orientales con el ministro del Interior, 6 de marzo de 1939, ADPO, caja $31 \mathrm{~W} / 274$

5. “Au cas où un afflux massif de réfugiés...", Le Petit Parisien, 25 de enero de 1939.

6. Circular del ministro de Sanidad Pública dirigida a los prefectos de: Aude, Ariège, Hérault y Tarn, 28 de enero de 1939, ADAUD, caja 4MD/603; ADARI, caja 113W/25; ADHE, caja 5M/561 y ADTA, caja 4M18/12.

7. Informe de la misión sanitaria en España de los médicos Lasnet, Wroczynski y Laigret, del 28 de diciembre de 1936 al 15 de enero de 1937, ADMAE, serie Service Français de la Société des Nations, 1937-1940, Dossiers Géographiques, Espagne, Guerre d'Espagne, legajo 2048. En dicho informe se refleja un análisis epidemiológico del tifus exantemático, viruela, disentería bacilar, paludismo y escarlatina entre otras.

8. Tanto la Union des Femmes de France como la Association des Dames Françaises son asociaciones de enfermeras de la Cruz Roja Francesa fundadas en 1884 y 1881 respectivamente (Duboys Fresney y Perrin, 2009, p. 17)

9. [Traducción propia] Bulletin de l'Union des Femmes de France, 1939, 20 (4), 1939, p. 118

10. Bulletin de I'Union des Femmes de France, 1939, 20 (2), pp. 34-35.

11. Circular del ministro de Sanidad Pública dirigida a los prefectos, 17 de febrero de 1939, ADAUD, caja 4M/603; ADTA, саja 4M/18-12 y 4M18/12; ADTG, caja 4M/4

12. Correspondencia del prefecto de Aude con el ministro de Sanidad Pública, 10 de febrero de 1939, ADAUD, caja $4 \mathrm{M} / 603$.

13. Correspondencia del ministro de Asuntos Extranjeros con el embajador de la República Francesa en Londres, 29 de enero de 1939, ADMAE, serie Europe 1918-1940, Espagne 1930-1940, legajo 187.

14. "Et si la ville tombe... réfugiés civils et militaires seront accueillis et répartis selon un plan rigoureux", Le Petit Parisien, 24 de enero de 1939.

15. Este término comienza a utilizarse de forma oficiosa en prensa durante el transcurso de la Guerra Civil y se cris- taliza tras el éxodo de 1939 en informes ministeriales. "Le problème des réfugiés espagnols", Le Temps, 21 de febrero de 1939. Este fenómeno ha sido estudiado por Cervera Gil, 2007, pp. 81-90.

16. 453.000 refugiados según documentación del Ministerio de Asuntos Extranjeros. "Opinion publique aux Etats-Units et situation des réfugiés espagnols se trouvant sur notre territoire", 19 de abril de 1939. ADMAE, serie Europa 1918-1940, España 1930-1940, libro 189, pp. 25-26.

17. Es la cifra que fijan los autores Louis Stein, Marie Claude Rafaneau y Génevieve Dreyfus-Armand en sus monográficos de 1979, 1995 y 2000 respectivamente. En el caso de Marie Claude no cita la fuente, Louis Stein se basa en prensa y Geneviève Dreyfus-Armand en el informe Valière del 9 de marzo de 1939. (Stein, 1983, p. 45; Rafaneau Boj, 1995, p. 47; Dreyfus-Armand, 2000, p. 53). El artículo de Cavaillon y Leclainche, del 7 de marzo de 1939, incrementa la cifra a 12.000 heridos y enfermos, fuente que cita Madeleine Souche (Souche, 2013, p. 14) en la misma línea que el prefecto de los Pirineos Orientales en su correspondencia con el Ministerio del Interior, 06 de marzo de 1939, ADPO, caja $31 \mathrm{~W} / 274$.

18. Información extraída de "La tournée d'inspection de MM. Albert Sarraut et Marc Rucart", Le Temps, 1 de febrero de 1939; "Les affaires d’Espagne. Le sous-préfet de Prades fait évacuer les blessés de Puigcerda", L'Ouest-Éclair, 9 de febrero de 1939; Estadísticas de heridos españoles en la estación de Cervera, del 31 de enero al 15 de febrero de 1939, ADPO, caja 31W/274 y Pruja, 2003, p. 35.

19. Correspondencia del ministro de Asuntos Extranjeros con el embajador de la República Francesa de Londres, 05 de junio de 1939, Paris, ADMAE, serie Europe 1918-1940, Espagne 1930-1940, legajo 189.

20. Estadísticas de heridos españoles en la estación de Cervera, del 31 de enero al 15 de febrero de 1939, ADPO, caja $31 \mathrm{~W} / 274$.

21. "La répartition des réfugiés dans les départements", Le Temps, 31 de enero de 1939.

22. [Traducción propia] Testimonio de la secretaria de la subprefectura de Prades (Grando, Queralt y Febrés, 2004, pp. 52-53)

23. Elaboración propia tras el análisis de la siguientes fuentes archivísticas: ADARI, caja 113W23; ADAUD, cajas 4MD/603 y $4 \mathrm{MD} / 673$; ADHE, cajas $12 \mathrm{~W} / 119,4 \mathrm{M} / 1081,4 \mathrm{M} / 1799$ y 4M/1801; ADHG, cajas X/293 y X/88; ADPO, caja 31W/274; ADTG, cajas $1 X / 1 / 36,1 X / 1 / 37$ y 4M/4; ANF, caja 2001022/9; ANP, cajas F1a/4533, F1a/4537, F7/14725, F7/14728, F7/14729, F7/14730, F7/14734 y F7/14735; Le Temps, 8 de marzo de 1939 y 24 de febrero de 1939

24. Libro de registro del hospital civil de Montauban, del 19 de noviembre de 1938 al 6 de octubre de 1939, ADTG, 
libro 1X1/36; Informe del inspector departamental de higiene de Tarn-et-Garonne, 24 de febrero de 1939, ADTG, caja $4 \mathrm{M} / 4$.

25. Libro de registro del hospital civil de Perpiñán, 1939, ADPO, libro 1787W/64.

26. Libro de registro del hospital civil de Perpiñán, 1939, ADPO, libro 1787W/64.

27. Correspondencia del prefecto de Ariège con el ministro de Sanidad Pública y el comisionado especial de Aude sobre el estado numérico de refugiados españoles en tratamiento en los diferentes hospitales del departamento de Aude, del 4 de marzo de 1939 al 21 de agosto de 1939, ADAUD, cajas 4MD/603 y $4 \mathrm{MD} / 673$.

28. Informe del inspector departamental de higiene de Lodève, 21 de febrero de 1939, ADHE, caja 4M/1799; Informe del inspector departamental de higiene de Lodève, 22 de febrero de 1939, ADHE, caja 5M/561.

29. Porcentaje calculado tras el análisis de las siguientes fuentes archivísticas ADARI, caja 113W23; ADAUD, cajas $4 \mathrm{MD} / 603$ y $4 \mathrm{MD} / 673$; ADHE, cajas $12 \mathrm{~W} / 119,4 \mathrm{M} / 1081$, $4 \mathrm{M} / 1799$ y $4 \mathrm{M} / 1801 ; A D H G$, cajas $\mathrm{X} / 293$ y $\mathrm{X} / 88$; ADPO, caja $31 \mathrm{~W} / 274$; ADTG, cajas $1 \mathrm{X} / 1 / 36,1 \mathrm{X} / 1 / 37$ y $4 \mathrm{M} / 4$; ANF, caja 2001022/9; ANP, cajas F1a/4533, F1a/4537, F7/14725, F7/14728, F7/14729, F7/14730, F7/14734 y F7/14735; Le Temps, 8 de marzo de 1939 y 24 de febrero de 1939.

30. Informe del inspector general de los servicios administrativos del Ministerio del Interior dirigido al ministro de Sanidad Pública, sobre la formación hospitalaria auxiliar que reciben los milicianos españoles en los Pirineos Orientales, Hérault y Gard, 22 de abril de 1939, ANP, caja F1a/4537.

31. "Une réunion à la préfecture des Pyrénées-Orientales", Le Petit Parisien, 20 de febrero de 1939; Le Populaire, 19 de febrero de 1939; "Le problème des réfugiés espagnols", Le Temps, 21 de febrero de 1939.

32. Se concedió una medalla de oro de las epidemias a la enfermera Pierson de la Association des Dames Françaises (ADF), la cual había trabajado en el antiguo hospital militar y había sido contagiada dentro del ejercicio de sus funciones. "Nouvelles diverses", Le Temps, 15 de abril de 1939. Un reconocimiento que no llegó a las 9 enfermeras españolas destinadas al servicio de contagiosos del hospital. Informe del general de los servicios administrativos del Ministerio del Interior, 22 de abril de 1939, ANP, caja F1a/4537.

33. [Traducción propia] Bulletin de l'Union des Femmes de France, 1939, 20 (4), 1939, p. 118.

34. Correspondencia del general Falgade con el prefecto de Aude sobre los españoles heridos, 9 de febrero de 1939, ADAUD, caja 4MD/603 y 606 .
35. Informe del general de los servicios administrativos del Ministerio del Interior, 22 de abril de 1939, ANP, caja F1a/4537.

36. "Des paquebots désarmés serviront d'hôpitaux", L'OuestÉclair, 9 de febrero de 1939.

37. Correspondencia del prefecto de Bouches-du-Rhône con el ministro de Salud Pública, 17 de febrero de 1939, ADBR, caja 4M/959; Correspondencia del ministro de Asuntos Extranjeros con el embajador de la República Francesa en Washington, 19 de abril de 1939, ADMAE, serie Europe 1918-1940, Espagne 1930-1939, legajo 189, pp. 25-26.

38. Informe del general de los servicios administrativos del Ministerio del Interior, 22 de abril de 1939, ANP, caja F1a/4537; Correspondencia del ministro de Sanidad Pública con el prefecto de los Pirineos Orientales sobre los gastos de los barcos hospitales, 15 de marzo de 1939, ADPO, caja $38 \mathrm{~W} / 149$.

39. "Les secours aux réfugiés espagnols", Bulletin de I'Union des Femmes de France, 1939, 20 (2), pp. 34-35.

40. Correspondencia del ministro de Asuntos Extranjeros con el embajador de la República Francesa en Washington sobre la opinión pública de los Estados Unidos y la situación de los refugiados españoles, 19 de abril de 1939, ADMAE, serie Europe 1918-1940, Espagne 1930-1939, legajo 189, pp. 25-26.

41. De las 70 enfermeras, 35 eran de la UFF y 10 de la ADF. Correspondencia, 27 de febrero de 1939, ADMAE, serie Service Français de la Société des Nations, 1917-1940, Dossiers Géographiques, Espagne, Guerre d'Espagne, legajo 2048, pp. 207-213. En el caso de los barcos Patria y Providence había 25 enfermeras de la UFF. Bulletin de I'Union des Femmes de France, 1939, 20 (3), pp. 86-87.

42. Arnaud, 1939; "Deux milles miliciens soignés à bord des paquebots "Patria» et "Providence» transformés en navires-hôpitaux", L'Ouest-Éclair, 21 de febrero de 1939; "Le soins aux blessés à bord des navires-hôpitaux «Patria» et "Providence»", Le Temps, 20 de febrero de 1939.

43. Bulletin de l'Union des Femmes de France, 1939, 20 (3), pp. 86-87; Correspondencia del prefecto de Bouches-duRhône con el ministro de Salud Pública, 17 de febrero de 1939, ADBR, 4M/959; Informe del inspector general de los servicios administrativos del Ministerio del Interior dirigido al ministro de Sanidad Pública, 22 de abril de 1939, ANP, caja F1a/4537.

44. [Traducción propia] Arnaud, 1939.

45. Normas en los establecimientos sanitarios de Marsella por el prefecto de Bouches-du-Rhône, febrero de 1939, ADBR, $4 \mathrm{M} / 959$.

46. Según la documentación de época, debemos considerar como personal auxiliar: enfermeras, enfermeros, conduc- 
tores de ambulancia, camilleros... Esto complica en ocasiones visibilizar las enfermeras que a su vez se dividían en: enfermeras diplomadas, de la Cruz Roja, de la Central Sanitaria Internacional, de la Oficina de Higiene Departamental, militares, auxiliares, voluntarias, estudiantes y en menor número religiosas. Es complicado en ciertas ocasiones intentar visibilizar el personal sanitario de enfermería.

47. Correspondencia del ministro de Sanidad Pública con el prefecto de Aude, 10 de febrero de 1939, ADAUD, caja 4MD/603; Contrato entre prefectura y médico francés, 23 de febrero de 1939, ADAUD, caja 4MD/603; Contrato entre prefectura y enfermera francesa, 10 de marzo de 1939, ADAUD, caja $4 \mathrm{MD} / 603$.

48. Informe del general de los servicios administrativos del Ministerio del Interior, 22 de abril de 1939, ANP, caja F1a/4537.

49. Documentación diversa, ANP, caja F1a/4537.

50. Esto es debido al importante número de profesionales sanitarios españoles que pasaron la frontera entre enero y marzo de 1939, entre los que encontramos: auxiliares, enfermeras, farmacéuticos, matronas, médicos, practicantes, odontólogos..

51. Circular del ministro de Salud Pública dirigida a prefectos, 3 de marzo de 1939, ADTG, caja 4M/4; ADAUD, caja 4MD/603; ADARI, caja 113W/22; ADHE, caja 12W/769 y ADBR, caja 4M/959; Informe del general de los servicios administrativos del Ministerio del Interior, 22 de abril de 1939, ANP, caja F1a/4537.

52. Correspondencia del prefecto de Aude con el ayuntamiento de Carcassonne, 1939, ADAUD, caja 4MD/670.

53. Correspondencia del prefecto de Ariège con el ministro del Interior, 8 de agosto de 1939, ADARI, caja 5M/148; Informe del comisario de Foix sobre los médicos militares españoles residentes en el Hospital de Foix, 6 de marzo de 1939, ADARI, caja 5M/148.

54. Informe del general de los servicios administrativos del Ministerio del Interior, 22 de abril de 1939, ANP, caja F1a/4537; Nota del ministro de Salud Pública, abril de 1939, ADMAE, serie Europe 1918-1940, Espagne 19301940, legajo 189.

55. Esta situación se dio desde los inicios de los éxodos a Francia como consecuencia de la Guerra Civil española. A modo de ejemplo, citaremos el caso de la enfermera refugiada Mercedes Gascón. Esta enfermera solicitó en julio de 1937, a la prefectura de La Drôme, que se le abonara el trabajo que realizaba junto la enfermera francesa departamental de higiene. Correspondencia, 21 de agosto de 1937, ADDR, caja 4M/643.
56. Correspondencia del ministro de Salud Pública con el servicio sanitario central de los refugiados de España, 6 de mayo de 1939, ADARI, caja 113W/22.

57. Relación de grandes inválidos españoles situados en el hospicio de Saint-André de Gaillac, 22 de abril de 1939, ADTA, caja 3HDT/M41; Relación de inútiles e inválidos en Tarn-et-Garonne, 11 de mayo de 1939, ADTG, caja 4M/4.

58. Correspondencia del ministro de Salud Pública con el prefecto de Tarn-et-Garonne, 4 de mayo de 1939, ADTA, caja 4M/18-12.

59. Situación particular de milicianos hospitalizados en el hospital mixto de Carcassonne, 30 de septiembre de 1939, ADAUD, caja 4MD/603.

60. Correspondencia del prefecto de Hérault con el ministro del Interior, 13 de mayo de 1939, caja ADHE, 1000W/234. Lo mismo ocurrió en el departamento de Aude, en julio de 1939 disminuyó el número de hospitalizados a la mitad, en agosto a un tercio y en septiembre apenas quedaban pacientes españoles en sus instalaciones sanitarias. Documentación diversa, ADAUD, cajas 4MD/603, 4MD/606, $4 \mathrm{MD} / 673$ y $4 \mathrm{MD} / 735$.

61. Correspondencia del general Noël con el prefecto de Aude, 12 de mayo de 1939, ADARI, caja 113W/32; Correspondencia del Dr. Bonafous con el prefecto de Aude, 9 de mayo de 1939, ADARI, caja $113 \mathrm{~W} / 32$.

62. Correspondencia del inspector departamental de higiene de Ariège con el prefecto de Ariège, 28 de julio de 1939, ADARI, caja $113 \mathrm{~W} / 32$.

63. Correspondencia del médico jefe del Hospital Auxiliar de Maraussan de Béziers con el prefecto de Hérault, 16 de junio de 1939, ADHE, caja 4M/1799; Correspondencia del ministro de Salud Pública con el prefecto de Hérault, 6 de junio de 1939, ADHE, caja 4M/1799.

64. Relación de enfermedades tratadas en el Hospital Auxiliar de Maraussan de Béziers desde el 20 de marzo al 14 de junio de 1939, ADHE, caja 4M/1796.

65. Correspondencia del ministro de Asuntos Extranjeros con el embajador de la República Francesa en Madrid, 1939, ADMAE, serie Europe 1918-1940, Espagne 1930-1940, legajo 189; Correspondencia del embajador de la República Francesa en Madrid con el ministro de Asuntos Extranjeros, 11 de noviembre de 1939, ADMAE, serie Europe 1918-1940, Espagne 1930-1940, legajo 189; Correspondencia de la presidenta del socorro aéreo con Quiñones de León, 27 de febrero de 1939, ADMAE, serie Europe 1918-1940, Espagne 1930-1940, legajo 187; Correspondencia del ministro de Asuntos Extranjeros con el embajador de la República Francesa en Madrid, 18 de marzo de 1939, ADMAE, serie Europe 1938-1940, Espagne 1930-1940, legajo 187. 


\section{BIBLIOGRAFÍA}

Alted Vigil, Alicia; Fernández Martínez, Dolores (2014), Tiempos de exilio y solidaridad: La maternidad suiza de Elna (1939-1944), Madrid, Universidad Nacional de Educación a Distancia.

Arnaud, Marcel (1939), “L'organisation et le fonctionnement du navire-hôpital "Maréchal-Lyautey»", Bulletin de l'Académie de Médecine, 18, pp. 671-678.

Cabeza Sánchez-Albornoz, Sonsoles (2000), “Balance historiográfico del exilio español: 1990-1999", Cuadernos de Historia Contemporánea, 22, pp. 135-157.

Cavaillon; Leclainche (1939), "Les problèmes sanitaires posés par l'exode en France des réfugiés espagnols", Bulletin de l'Académie de Médecine, 9, pp. 328-336.

Cervera Gil, Javier (2007), La guerra no ha terminado. El exilio español en Francia. 1944-1953, Madrid, Taurus.

Dreyfus-Armand, Geneviève (2000), El exilio de los republicanos españoles en Francia. De la guerra civil a la muerte de Franco, Barcelona, Crítica.

Duboys Fresney, Catherine; Perrin, Georgette (2009), Le métier d'infirmière en France. Du métier d'infirmière à l'exercice professionnel des soins infirmiers, Paris, Presses Universitaires de France.

Font Agulló, Jordi; Gaitx Moltó, Jordi (2014), “L'exili de 1939. Un estat de la qüestió entre dues commemoracions (20092014)", Franquisme \& Transició, 2, pp. 231-280.

González Canalejo, Carmen (2009), “María García Torrecillas: El paradigma de las mujeres en el exilio republicano (19361943)", Arenal, 1 (16), pp. 175-187.

Grando, René; Queralt, Jacques; Febrés, Xavier (2004), Camps du Mépris. Des chemins de l'exil à ceux de la résistance. 1939-1945. Canet, Trabucaire.

Guerra, Francisco (2003), La Medicina en el exilio republicano, Madrid, Universidad de Alcalá.

Hague, Jean Louis (1997), “Quelques aspects de la sociabilité des miliciens espagnols réfugiés dans le Roussillon (19371940)", Provence Historique, (187), pp. 151-161.

Harana, Lola (2012), “Los barcos-hospital franceses: Los otros barcos del exilio". En: Lough, Francis; Buffery, Helena; Marcer, Elisenda; Sánchez, Antonio (coords.), Geografías del exilio republicano español, Birmingham, Centre for the Study of Hispanic Exile, pp. 35-46.

Hervás i Puyal, Carles (2004), Sanitat a Catalunya durant la República i la Guerra Civil. Política i Organització sanitàries: l'impacte del conflicte bèl.lic, Tesis doctoral, Universitat Pompeu Fabra.
Hervás i Puyal, Carles (2014), La xarxa hospitalària a Catalunya durante la Guerra Civil (1936-1939), Manresa, Publicacions de l'Arxiu Històric de les Ciènces de la Salut.

Hoyos Puente, Jorge de (2012), "Últimas aportaciones a los estudios de los exilios españoles contemporáneos", Ayer, 85 (1), pp. 229-242

Llorens, Vicente (1976), "La emigración republicana de 1939". En: Abellán, José Luis (dir.), Emigraciones de la España Moderna, Madrid, Taurus, pp. 25-93.

Malo, Eric (2009), Le camp de Noé 1941-1947, Pau, Cairn.

Martínez Vidal, Àlvar; Zarzoso Orellana, Alfons (2010), “La obsesión del retorno. El exilio médico catalán en Francia”, Mètode, anuario, pp. 59-63.

Martínez Vidal, Àlvar (2013a), L'hôpital Varsovie. Exil, médecine et résistance (1944-1950), Portet-sur-Garonne, Loubatières.

Martínez Vidal, Àlvar (2013b), “Metges catalans refugiats a França. Observació clínica i recerca científica als camps de concentració (1939-1942)". En: Barrié, Roger; Camiade, Martine; Font, Jordi (dirs.), 2e Actes du séminaire transfrontalier. Déplacements forcés et exils en Europe au XXe siècle. Le corps et l'esprit, Perpiñán, Talaia, pp. 105-129.

Mirón-González, Rubén (2015), “Fuentes archivísticas para el estudio sanitario del exiliado español en el sur de Francia (1936-1945)". En: Bellver Loizaga, Vicent; D’Amaro, Francesco; Molina Puertos, Isabel; Ramos Tolosa, Jorge (coords.), "Otras voces, otros ámbitos": Los sujetos y su entorno. Nuevas perspectivas de la historia sociocultural, Valencia, Universitat de València, pp. 208-211.

Mirón-González, Rubén; González-García, Alberto (2017), "Asistencia sanitaria entre camarotes. Los barcos hospitales del exilio". En: IV Encuentro Internacional de Jóvenes Investigadores en Historia Contemporánea (Zaragoza, 6-8 septiembre de 2017).

Parello, Vincent (2014), "La politique sanitaire du gouvernement français à l'égard des réfugiés espagnols de la guerre civile", Bulletin Hispanique, 1 (116), pp. 247-263.

Peschanski, Denis (2002), La France des camps. L'internement, 1938-1946. [Paris], Gallimard.

Peschanski, Denis (2005), "Morbilité et mortalité dans la France des camps". En: Von Bueltzingsloewen, Isabelle (dir.), "Morts d'inanition". Famine et exclusions en France sous l'Ocupation, Rennes, Presses Universitaires de Rennes, pp. 201-212.

Pruja, Jean Claude (2003), Premiers camps de l'exil espagnol. Prats-De-Mollo, 1939, Saint-Avertin, Alan Sutton.

Rafaneau Boj, Marie Claude (1995), Los campos de concentración de los refugiados españoles en Francia (1939-1945), Barcelona, Omega. 
Rubio, Javier (1974), La emigración española a Francia, Esplugas de Llobregat, Ariel.

Ruiz-Berdún, María Dolores; Bladé i Font, Artur (2016), "Una matrona en el exilio republicano: Cinta Font Margalef", Medicina e historia, 3 (36), pp. 16-26.

Simón Porolli, Paula (2011), Por los caminos de la palabra. Exilio republicano español y campos de concentración franceses: Una historia del testimonio, Tesis doctoral, Universidad Autónoma de Barcelona.

Solé, Felip; Tuban, Grégory (2011), Camp d'Argelers (19391942), Valls, Cossetània.
Souche, Madeleine (2013), "Témoignages sur les pathologies dans les camps d'internement (1939-1942)". En: Barrié, Roger; Camiade, Martine; Font, Jordi (dirs.), 2e Actes du séminaire transfrontalier. Déplacements forcés et exils en Europe au XXe siècle. Le corps et l'esprit, Perpiñán, Talaia, pp. 11-66.

Stein, Louis (1981), Par-delà l'exil et la mort. Les républicains espagnols en France, Aubin, Mazarine.

Stein, Louis (1983), Más allá de la muerte y del exilio, Barcelona, Plaza \& Janes.

Wingeate Pike, David (1969), Vae victis! Los republicanos españoles refugiados en Francia 1939-1944, Colombes, Ruedo ibérico.

\section{ANEXOS}

Centros asistenciales y municipios que acogieron heridos y enfermos por región y departamento. De enero a septiembre de 1939. Elaboración propia.

\begin{tabular}{|c|c|c|c|c|}
\hline CENTROS ASISTENCIALES Y MUNICIPIOS & HOMBRES & MUJERES & NIÑOS/AS & TOTAL \\
\hline AQUITAINE & 1617 & 0 & 0 & 1617 \\
\hline Basses-Pyrénées (Pyrénées-Atlantiques) & 67 & 0 & 0 & 67 \\
\hline Hospital de Bayonne & 67 & 0 & 0 & 67 \\
\hline Hospital de Pau & 0 & 0 & 0 & 0 \\
\hline Hospital de Saint-Jean-de-Luz & 0 & 0 & 0 & 0 \\
\hline Dordogne & 1200 & 0 & 0 & 1200 \\
\hline Formación sanitaria de Clairvivre & 1200 & 0 & 0 & 1200 \\
\hline Gironde & 116 & 0 & 0 & 116 \\
\hline Barco hospital Habana en Bordeaux & 116 & 0 & 0 & 116 \\
\hline Landes & 181 & 0 & 0 & 181 \\
\hline Centro de Dax & 181 & 0 & 0 & 181 \\
\hline Lot-et-Garonne & 53 & 0 & 0 & 53 \\
\hline Hospital auxiliar de Aiguillon & 42 & 0 & 0 & 42 \\
\hline Hospital de Agen & 3 & 0 & 0 & 3 \\
\hline Hospital de Marmande & 8 & 0 & 0 & 8 \\
\hline AUVERGNE & 99 & 36 & 19 & 154 \\
\hline Allier & 27 & 36 & 19 & 82 \\
\hline Hospital psiquiátrico de Yzeure & 11 & 24 & 7 & 42 \\
\hline Hospitalizados en Montlucon & 2 & 3 & 0 & 5 \\
\hline Hospitalizados en Moulins & 14 & 9 & 12 & 35 \\
\hline Cantal & 72 & 0 & 0 & 72 \\
\hline Heridos y Enfermos en Aurillac & 35 & 0 & 0 & 35 \\
\hline Heridos y Enfermos en Chautes-Aigues & 10 & 0 & 0 & 10 \\
\hline
\end{tabular}




\begin{tabular}{|c|c|c|c|c|}
\hline CENTROS ASISTENCIALES Y MUNICIPIOS & HOMBRES & MUJERES & NIÑOS/AS & TOTAL \\
\hline Heridos y Enfermos en Mouret & 15 & 0 & 0 & 15 \\
\hline Heridos y Enfermos en Saint-Illide & 12 & 0 & 0 & 12 \\
\hline BASSE-NORMANDIE & 15 & 75 & 70 & 160 \\
\hline Calvados & 7 & 57 & 57 & 121 \\
\hline Caridad de Caen & 0 & 7 & 3 & 10 \\
\hline Caridad de Saint-Vigor-le-Grand & 0 & 9 & 8 & 17 \\
\hline Hospicios de Bayeux & 0 & 12 & 16 & 28 \\
\hline Hospital de Caen & 7 & 29 & 30 & 66 \\
\hline La Manche & 0 & 6 & 8 & 14 \\
\hline Hospital Marítimo de Gouberville & 0 & 3 & 4 & 7 \\
\hline Hospital Pasteur de Gouberville & 0 & 3 & 4 & 7 \\
\hline Orne & 8 & 12 & 5 & 25 \\
\hline Sanatorio de Lemaire & 8 & 12 & 5 & 25 \\
\hline BOURGOGNE & 37 & 19 & 14 & 70 \\
\hline Côte-d'Or & 4 & 18 & 9 & 31 \\
\hline Hospitalizados en Auxonne & 4 & 11 & 7 & 22 \\
\hline Hôtel Dieu en Beaune & 0 & 7 & 2 & 9 \\
\hline Nièvre & 31 & 1 & 5 & 37 \\
\hline Hospital de Clamecy & 6 & 0 & 0 & 6 \\
\hline Hospital de Lormes & 0 & 1 & 5 & 6 \\
\hline Hospital de Saint-Pierre-le-Moutier & 15 & 0 & 0 & 15 \\
\hline Hospital de Varzy & 10 & 0 & 0 & 10 \\
\hline Yonne & 2 & 0 & 0 & 2 \\
\hline Hospital de Auxerre & 2 & 0 & 0 & 2 \\
\hline BRETAGNE & 252 & 94 & 25 & 371 \\
\hline Côtes-du-Nord (Côtes-d'Armor) & 107 & 0 & 0 & 107 \\
\hline Hospicio de Saint-Brieuc & 64 & 0 & 0 & 64 \\
\hline Hospital de Dinan & 23 & 0 & 0 & 23 \\
\hline Hospital de Guingamp & 20 & 0 & 0 & 20 \\
\hline Morbihan & 145 & 94 & 25 & 264 \\
\hline Hospital de Vannes & 145 & 94 & 25 & 264 \\
\hline CENTRE & 20 & 90 & 107 & 217 \\
\hline Cher & 18 & 59 & 54 & 131 \\
\hline Hospital de Saint-Amand & 18 & 59 & 54 & 131 \\
\hline Indre & 0 & 0 & 17 & 17 \\
\hline Hospital del Centro de Le Blanc & 0 & 0 & 17 & 17 \\
\hline Loiret & 2 & 11 & 16 & 29 \\
\hline Departamento & 2 & 11 & 16 & 29 \\
\hline
\end{tabular}




\begin{tabular}{|c|c|c|c|c|}
\hline CENTROS ASISTENCIALES Y MUNICIPIOS & HOMBRES & MUJERES & NIÑOS/AS & TOTAL \\
\hline Loir-et-Cher & 0 & 20 & 20 & 40 \\
\hline Departamento & 0 & 20 & 20 & 40 \\
\hline HAUTE-NORMANDIE & 15 & 30 & 33 & 78 \\
\hline Eure & 0 & 18 & 0 & 18 \\
\hline Hospital de Bernay & 0 & 18 & 0 & 18 \\
\hline Seine-Inférieure (Seine-Maritime) & 15 & 12 & 33 & 60 \\
\hline Hospital de Canteleu & 0 & 0 & 5 & 5 \\
\hline Sanatorio de Rouen & 15 & 12 & 28 & 55 \\
\hline LANGUEDOC-ROUSSILLON & 6046 & 153 & 71 & 6270 \\
\hline Aude & 543 & 97 & 44 & 684 \\
\hline Hospital de Fanjeaux & 17 & 0 & 0 & 17 \\
\hline Hospital de Lezignan-Corbières & 13 & 3 & 9 & 25 \\
\hline Hospital de Narbonne & 130 & 16 & 11 & 157 \\
\hline Hospital mixto de Castelnaudary & 167 & 8 & 2 & 177 \\
\hline Hospital y hospicio de Limoux & 1 & 21 & 22 & 44 \\
\hline Hospital, hospicio y maternidad de Carcassonne & 215 & 49 & 0 & 264 \\
\hline Gard & 418 & 0 & 0 & 418 \\
\hline Centro médico Gaston Domergue de Nîmes & 21 & 0 & 0 & 21 \\
\hline Hospital auxiliar católico en Grau-du-Roi & 160 & 0 & 0 & 160 \\
\hline $\begin{array}{l}\text { Hospital auxiliar en colonia de vacaciones laica de Grau-du- } \\
\text { Roi }\end{array}$ & 80 & 0 & 0 & 80 \\
\hline $\begin{array}{l}\text { Hospital auxiliar protestante en castillo Lenhart de Grau-du- } \\
\text { Roi }\end{array}$ & 157 & 0 & 0 & 157 \\
\hline Hérault & 1835 & 56 & 27 & 1918 \\
\hline Campo de las Juventudes Laicas y Republicanas de Sète & 225 & 0 & 0 & 225 \\
\hline Campo de vacaciones de Saint-Bauzille-de-Putois & 23 & 56 & 27 & 106 \\
\hline Clínicas Saint-Eloi de Montpellier & 106 & 0 & 0 & 106 \\
\hline Hospital auxiliar Maraussan en Béziers & 700 & 0 & 0 & 700 \\
\hline Hospital de Clermont L'Hérault & 50 & 0 & 0 & 50 \\
\hline Hospital de Montpellier & 6 & 0 & 0 & 6 \\
\hline Hospital Privado de Lamalou-les-Bains (Centro Sanitario 2) & 20 & 0 & 0 & 20 \\
\hline Hospital temporal de Sète & 225 & 0 & 0 & 225 \\
\hline Hospital-hospicio de Lodève & 25 & 0 & 0 & 25 \\
\hline Hotel de France de Lamalou-les-Bains (Centro Sanitario 2) & 39 & 0 & 0 & 39 \\
\hline Hotel Bains de Lamalou-les-Bains (Centro Sanitario 2) & 60 & 0 & 0 & 60 \\
\hline Hotel Palmiers de Lamalou-les-Bains (Centro Sanitario 2) & 21 & 0 & 0 & 21 \\
\hline Hotel Thermes de Lamalou-les-Bains (Centro Sanitario 2) & 67 & 0 & 0 & 67 \\
\hline Hotel Centre de Lamalou-les-Bains (Centro Sanitario 2) & 41 & 0 & 0 & 41 \\
\hline Hotel Nord de Lamalou-les-Bains (Centro Sanitario 2) & 70 & 0 & 0 & 70 \\
\hline Hotel Mas de Lamalou-les-Bains (Centro Sanitario 2) & 41 & 0 & 0 & 41 \\
\hline
\end{tabular}




\begin{tabular}{|c|c|c|c|c|}
\hline CENTROS ASISTENCIALES Y MUNICIPIOS & HOMBRES & MUJERES & NIÑOS/AS & TOTAL \\
\hline Hotel Nouvel de Lamalou-les-Bains (Centro Sanitario 2) & 25 & 0 & 0 & 25 \\
\hline Hôtel-Dieu & 15 & 0 & 0 & 15 \\
\hline Villa Muguets de Lamalou-les-Bains (Centro Sanitario 2) & 12 & 0 & 0 & 12 \\
\hline Villa Platanes (Centro Sanitario 2) & 20 & 0 & 0 & 20 \\
\hline Villa Gaujal de Lamalou-les-Bains (Centro Sanitario 2) & 14 & 0 & 0 & 14 \\
\hline Villa Henri Gulid (Centro Sanitario 2) & 14 & 0 & 0 & 14 \\
\hline Villa Jougla de Lamalou-les-Bains (Centro Sanitario 2) & 8 & 0 & 0 & 8 \\
\hline Villa Verd (Centro Sanitario 2) & 8 & 0 & 0 & 8 \\
\hline Lozère & 5 & 0 & 0 & 5 \\
\hline Departamento de Lozère & 5 & 0 & 0 & 5 \\
\hline Pyrénées-Orientales & 3245 & 0 & 0 & 3245 \\
\hline Antiguo Hospital Militar & 679 & 0 & 0 & 679 \\
\hline Barcos hospitales Maréchal-Lyautey y Asni & 1716 & 0 & 0 & 1716 \\
\hline Hospital auxiliar Saint-Louis & 450 & 0 & 0 & 450 \\
\hline Hospital Saint-Jean de Perpiñán & 400 & 0 & 0 & 400 \\
\hline LIMOUSIN & 116 & 73 & 56 & 245 \\
\hline Corrèze & 101 & 2 & 2 & 105 \\
\hline Hospital de Brive & 75 & 0 & 0 & 75 \\
\hline Hospital de Tulle & 17 & 2 & 2 & 21 \\
\hline Hospital de Ussel & 9 & 0 & 0 & 9 \\
\hline Creuse & 14 & 48 & 40 & 102 \\
\hline Hospital de Guéret & 14 & 48 & 40 & 102 \\
\hline Haute-Vienne & 1 & 23 & 14 & 38 \\
\hline Hospital de Limoges & 1 & 23 & 14 & 38 \\
\hline MIDI-PYRÉNÉES & 1480 & 167 & 153 & 1812 \\
\hline Ariège & 62 & 57 & 20 & 139 \\
\hline Antiguo Hospicio de Saverdun & 0 & 28 & 14 & 42 \\
\hline Hospicio de Sabart en Tarascon & 15 & 1 & 0 & 16 \\
\hline Hospital de Foix & 0 & 5 & 0 & 5 \\
\hline Hospital de Mirepoix & 4 & 5 & 0 & 9 \\
\hline Hospital de Saint-Lizier & 9 & 0 & 0 & 9 \\
\hline Hospital Saint-Louis de Ax-les-Thermes & 5 & 3 & 0 & 8 \\
\hline Hospitalizados en Bastide-de-Sérou & 6 & 0 & 0 & 6 \\
\hline Hospitalizados en Lavelanet & 3 & 0 & 0 & 3 \\
\hline Hospitalizados en Mazeres & 0 & 14 & 6 & 20 \\
\hline Hospitalizados en Saint-Girons & 20 & 1 & 0 & 21 \\
\hline Aveyron & 58 & 26 & 10 & 94 \\
\hline Hospital de L'Espalion & 3 & 0 & 0 & 3 \\
\hline Hospital de Millau & 10 & 0 & 0 & 10 \\
\hline
\end{tabular}




\begin{tabular}{|c|c|c|c|c|}
\hline CENTROS ASISTENCIALES Y MUNICIPIOS & HOMBRES & MUJERES & NIÑOS/AS & TOTAL \\
\hline Hospital de Rodez & 26 & 26 & 10 & 62 \\
\hline Hospitalizados en Decazeville & 1 & 0 & 0 & 1 \\
\hline Hospitalizados en Villefranche & 18 & 0 & 0 & 18 \\
\hline Gers & 69 & 0 & 0 & 69 \\
\hline Hospital auxiliar de Auch (Caserna Lannes) & 69 & 0 & 0 & 69 \\
\hline Haute-Garonne & 175 & 0 & 0 & 175 \\
\hline Hospital auxiliar nำ & 119 & 0 & 0 & 119 \\
\hline Hospital auxiliar $n=2$ & 56 & 0 & 0 & 56 \\
\hline Tarn & 854 & 84 & 123 & 1061 \\
\hline Clínica psiquiátrica de Font d’Aurelle & 800 & 0 & 0 & 800 \\
\hline Hospicio Saint-André de Gaillac & 38 & 0 & 2 & 40 \\
\hline Hospitalizados en Albi & 15 & 0 & 0 & 15 \\
\hline Preventorio de la Bassine en Jigounet & 1 & 76 & 98 & 175 \\
\hline Preventorio Saint-Michel en Lagune-les-Bains & 0 & 8 & 23 & 31 \\
\hline Tarn-et-Garonne & 262 & 0 & 0 & 274 \\
\hline Hospital auxiliar de la Ville des Rosiers & 0 & 0 & 0 & 0 \\
\hline Hospital de Montauban & 200 & 0 & 0 & 200 \\
\hline Localidad de Larrazet & 0 & 0 & 0 & 1 \\
\hline Localidad de Lavilledieu & 0 & 0 & 0 & 10 \\
\hline Localidad de Montaigu & 0 & 0 & 0 & 1 \\
\hline Refugio de Caussade & 62 & 0 & 0 & 62 \\
\hline NORD-PAS-DE-CALAIS & 44 & 172 & 209 & 425 \\
\hline Pas-de-Calais & 44 & 172 & 209 & 425 \\
\hline Hospital Bouville en Berck-Plage & 26 & 0 & 8 & 34 \\
\hline Hospital Cazin-Perrochaud en Berck-sur-Mer & 1 & 2 & 35 & 38 \\
\hline Hospital Victor Menard en Berck-sur-Mer & 0 & 25 & 56 & 81 \\
\hline Instituto Carlot & 0 & 17 & 5 & 22 \\
\hline Sanatorio Boutillier en Berck-Plage & 9 & 35 & 21 & 65 \\
\hline Sanatorio Lemaire & 7 & 22 & 13 & 42 \\
\hline Sanatorio Quettier en Berck-sur-Mer & 1 & 49 & 24 & 74 \\
\hline Sanatorio Vincent de Berck & 0 & 22 & 47 & 69 \\
\hline PAYS DE LA LOIRE & 661 & 65 & 2 & 1628 \\
\hline Loire-Inférieure (Loire-Atlantique) & 600 & 0 & 0 & 600 \\
\hline Departamento & 600 & 0 & 0 & 600 \\
\hline Maine-et-Loire & 5 & 0 & 0 & 5 \\
\hline Hospital de Angers & 5 & 0 & 0 & 5 \\
\hline Mayenne & 56 & 65 & 2 & 123 \\
\hline Asilo de Mayenne & 14 & 10 & 0 & 24 \\
\hline
\end{tabular}




\begin{tabular}{|c|c|c|c|c|}
\hline CENTROS ASISTENCIALES Y MUNICIPIOS & HOMBRES & MUJERES & NIÑOS/AS & TOTAL \\
\hline Maternidad de Mayenne & 42 & 55 & 2 & 99 \\
\hline Sarthe & 0 & 0 & 0 & 900 \\
\hline Hospital de Le Mans & 0 & 0 & 0 & 900 \\
\hline POITOU-CHARENTES & 6 & 15 & 58 & 79 \\
\hline Charente-Inférieure (Charente-Maritime) & 0 & 0 & 47 & 47 \\
\hline $\begin{array}{l}\text { Enfermería del campamento de verano "La Maison } \\
\text { Heureuse" }\end{array}$ & 0 & 0 & 15 & 15 \\
\hline $\begin{array}{l}\text { Enfermería del campamento de verano "L'Abbaye de } \\
\text { l'Ormeau" }\end{array}$ & 0 & 0 & 32 & 32 \\
\hline Vienne & 6 & 15 & 11 & 32 \\
\hline Departamento & 6 & 15 & 11 & 32 \\
\hline PROVENCE-ALPES-CÔTE D'AZUR & 2372 & 23 & 11 & 2406 \\
\hline Basses-Alpes (Alpes-de-Haute-Provence) & 5 & 23 & 11 & 39 \\
\hline Hospital de Digne & 5 & 23 & 11 & 39 \\
\hline Bouches-du-Rhône & 2350 & 0 & 0 & 2350 \\
\hline Barcos hospitales Patria y Providence & 2350 & 0 & 0 & 2350 \\
\hline Vaucluse & 17 & 0 & 0 & 17 \\
\hline Hospital de Avignon & 10 & 0 & 0 & 10 \\
\hline Hospital de Carpentras & 3 & 0 & 0 & 3 \\
\hline Hospital de Orange & 4 & 0 & 0 & 4 \\
\hline RHÔNE-ALPES & 458 & 32 & 30 & 520 \\
\hline Ain & 8 & 32 & 30 & 70 \\
\hline Hospital de Oyonnax & 8 & 32 & 30 & 70 \\
\hline Loire & 450 & 0 & 0 & 450 \\
\hline Departamento & 450 & 0 & 0 & 450 \\
\hline TOTAL GENERAL & 13.238 & 1.044 & 858 & 16.052 \\
\hline
\end{tabular}

Fuente: ADARI, 113W23; ADAUD, 4MD/603; 4MD/673; ADHE, 12W/119; 4M/1081; 4M/1799; 4M/1801; ADHG, X/293; X/88; ADPO, 31W/274; ADTG, 1X/1/36; 1X/1/37; 4M/4; ANF, 2001022/9; ANP, F1a/4533; F1a/4537; F7/14725; F7/14728; F7/14729; F7/14730; F7/14734; F7/14735; Le Temps (Paris), 08/03/1939; 24/02/1939. Elaboración propia. 